\title{
Clearly Defining Re-exposure Protection And Vaccine Efficacy Statistical Results
}

Copyright David E. Epperly, Inflection Technologies Corp.

Created: 2021.0115a

Revised: 2021.0305c

Publications often discuss how vaccines / prior infections may result in future protection from a virus. For example, a recent publication stated "83\% protection" after recovering from a primary viral infection. Is a "pragmatically useful" number higher or lower? And what does the number mean? This depends on what is meant by "protection" and the data used in determination of the number.

It is well accepted that immune response (not necessarily viral damage) often causes headaches, myalgia, and fatigue, (even chills/fever). Recently approved mRNA vaccines (which involve only Spike protein and no infectious viral aspect) stimulate immune response and may present these symptoms. ${ }^{1}$

How are "symptomatic" cases defined? Are they symptoms unique to viral damage like sore throat, congestion, cough? Or should brief symptoms solely related to immune response be included in the definition?

Are asymptomatic infections [properly] categorized as a protective result?

What PCR Ct defines "infection"? How should high Ct count / borderline positive / essentially non-shedding tests be categorized?

It is proposed that Ct counts be grouped into categories of "strongly shedding", "moderately shedding", "borderline positive / lightly shedding", and "negative". These categories could identify a clinically useful spectrum of PCR "positiveness". Further, it may be reasonable to assume that viable virus is likely when Ct counts are low, but not necessarily with borderline positive $\mathrm{Ct}$ counts. PCR tests detect viral RNA presence, but do not indicate virus viability. ${ }^{2}$

Serious cases that result in hospital admission could be a category that would help identify the level of "protection", or lack thereof.

If, for example, only 15 of 44 people with "positive" PCR indications are found symptomatic, is it appropriate to use the 15 or the 44 in determining the statistical statement of "protection"? And should brief headache / myalgia with no sore throat, cough, congestion be considered "symptomatic" even though it may just be a rapid secondary immune response to re-exposure? Does PCR Ct count suggest significant shedding indicating MMID similarity ${ }^{3}$ ?

It is proposed that studies should use improved definitions to specify categories when discussing "protection" and "efficacy". The most important indications for "protection" might include:

- What is the "class" of symptom characteristics?

- Is there significant virally caused tissue damage?

- Is there significant shedding?

- Did hospital admission occur? ICU?

It is important to state statistical study observations across a set of categorical interpretations. And popular press should respectfully convey the statistics and definitions. 
An example Parametric Efficacy Table format is proposed (numbers are fictional but somewhat thoughtful):

\begin{tabular}{|l|l|l|}
\hline Prevented Scenario \Vaccination Status & After Only 1 Dose & After 2 Doses \\
\hline PCR Borderline Positive *1 31 to 35? & $70 \%$ & $85 \%$ \\
\hline PCR Moderate Shedding *1 25 to <31? & $92 \%$ & $97 \%$ \\
\hline PCR Strong Shedding *1 <25? & $97 \%$ & $98 \%$ \\
\hline Immune Response Symptoms Present & $60 \%$ & $90 \%$ \\
\hline Mild Viral Damage Symptoms Present (cough, sore throat) & $88 \%$ & $94 \%$ \\
\hline Moderate Symptoms Present (hypoxemia, minor CAT) & $97 \%$ & $98 \%$ \\
\hline Severe Symptoms Present (hypoxia, severe CAT, thrombi) & $99.9 \%$ & $99.95 \%$ \\
\hline Hospital / Clinical Visit & $96 \%$ & $97 \%$ \\
\hline Hospital Admission & $97 \%$ & $98 \%$ \\
\hline ICU Admission & $99.8 \%$ & $99.75 \% * 2$ \\
\hline Terminal & $99.99 \%$ & $99.999 \%$ \\
\hline
\end{tabular}

*1 Ct count either regularly monitored during trial or at points following symptom presentation

*2 inconsistency simulates real life where near equivalence can result in theoretical mismatch

Items highlighted are what have typically been presented in past efficacy trials.

Most efficacy studies collect this data but do not present it. For example, the article Evidence For COVID-19 Vaccine Deferred Dose 2 Boost Timing 4 referenced data from formal NEJM publications and FDA EUA application documents to obtain a complete view of case severity data that preferably would have been summarized in the NEJM publications.

Additionally, some of this data is presented in discussion when it preferably would be part of the results; where discussion could note nuances and theoretical mismatches as simulated here in $(* 2)$ above.

Studies must allow proper seroconversion time (at least 7 days, preferably 14 days or longer) past vaccination in efficacy calculations. An example of lacking immune response / seroconversion accommodation can be found in Safety and Efficacy of the BNT162b2 mRNA Covid-19 Vaccine ${ }^{5,4}$ where the calculation was made starting at the time of vaccination which left no time for the vaccine to become effective as the immune response had not yet began / culminated.

Moderate Symptoms, Severe Symptoms, Clinical Visit, Admission, ICU, and Terminal categories must accommodate the period in which disease progresses in calculation. For example, if a patient is Admitted on day 30 past vaccination, and was found PCR positive / symptomatic on day 3 past vaccination, the case should be excluded from vaccine arm efficacy calculation as the patient was infected prior to seroconversion "culmination". For an example of where this issue appears problematic, see BNT162b2 mRNA Covid-19 Vaccine in a Nationwide Mass Vaccination Setting ${ }^{6}$

Suggested Tweet: "Efficacy" and "reinfection", should be defined parametrically and statistical data collected for each category in a table. New standard. Admitted? ICU? Terminal? Symptomatic? What kind of symptoms? Viral damage minor or serious? Did they shed? How much?

\section{References And Further Reading}

\footnotetext{
${ }^{1}$ FACT SHEET FOR RECIPIENTS AND CAREGIVERSEMERGENCY USE AUTHORIZATION (EUA) OF THE MODERNA COVID-19 VACCINE TO PREVENT CORONAVIRUS DISEASE 2019 (COVID-19) IN INDIVIDUALS 18 YEARS OF AGE AND OLDER, https://www.fda.gov/media/144638/download, FACT SHEET FOR RECIPIENTS AND CAREGIVERSEMERGENCY USE AUTHORIZATION (EUA) OFTHE PFIZER-BIONTECH CO VID-19 VACCINE TO PREVENT CORONAVIRUS DISEASE 2019 (CO VID-19) IN INDIVIDUALS 16 YEARS OF AGE AND OLDER, https://www.fda.gov/media/144414/download
} 
${ }^{2}$ Rodríguez, R. A., Pepper, I. L., \& Gerba, C. P. (2009). Application of PCR-based methods to assess the infectivity of enteric viruses in environmental samples. Applied and environmental microbiology, 75(2), 297-307. https://doi.org/10.1128/AEM.01150-08

${ }^{3}$ Memoli MJ, Czajkowski L, et al., Validation of the wild-type influenza a human challenge model H1N1pdMIST: an A(H1N1) pdm09 dose-finding investigational new drug study. Clin Infect Dis. 2015;60:693-702. doi: 10.1093/cid/ciu924.

https://www.ncbi.nlm.nih.gov/pmc/articles/PMC4342672/

${ }^{4}$ Epperly, David. 2021. "Evidence For COVID-19 Vaccine Deferred Dose 2 Boost Timing." SSRN Electronic Journal, January. Elsevier BV. doi:10.2139/ssrn.3760833. https://doi.org/10.2139/ssrn.3760833

${ }^{5}$ Polack, Fernando P., Stephen J. Thomas, Nicholas Kitchin, Judith Absalon, Alejandra Gurtman, Stephen Lockhart, John L. Perez, et al. "Safety and Efficacy of the BNT162b2 mRNA Covid-19 Vaccine." New England Journal of Medicine 383, no. 27 (December 31, 2020): 2603-2615. doi:10.1056/nejmoa2034577. https://doi.org/10.1056/nejmoa2034577

${ }^{6}$ Dagan, N., Barda, N., Kepten, E., Miron, O., Perchik, S., Katz, M. A., ... Balicer, R. D. (2021). BNT162b2 mRNA Covid-19 Vaccine in a Nationwide Mass Vaccination Setting. New England Journal of Medicine. doi:10.1056/nejmoa2101765.

https://doi.org/10.1056/nejmoa2101765 